\title{
Electroanalytical Sensing of Bromides Using Radiolytically Synthesized Silver Nanoparticle Electrocatalysts
}

\author{
Jadranka Milikić, ${ }^{1}$ Ivan Stoševski, ${ }^{1}$ Jelena Krstić, ${ }^{2}$ Zorica Kačarević-Popović, \\ Šćepan Miljanić, ${ }^{1}$ and Biljana Šljukić ${ }^{1}$ \\ ${ }^{1}$ Faculty of Physical Chemistry, University of Belgrade, Studentski trg 12-16, 11158 Belgrade, Serbia \\ ${ }^{2}$ Vinča Institute of Nuclear Sciences, University of Belgrade, P.O. Box 522, 11001 Belgrade, Serbia \\ Correspondence should be addressed to Biljana Šljukić; biljka@ffh.bg.ac.rs
}

Received 16 May 2017; Revised 26 August 2017; Accepted 30 August 2017; Published 17 October 2017

Academic Editor: Boryana M. Nikolova-Damyanova

Copyright (C) 2017 Jadranka Milikić et al. This is an open access article distributed under the Creative Commons Attribution License, which permits unrestricted use, distribution, and reproduction in any medium, provided the original work is properly cited.

Monitoring bromides $\left(\mathrm{Br}^{-}\right)$is of crucial importance since bromates, potential human carcinogens, are formed during ozonation of water containing bromides in concentrations $>100 \mu \mathrm{g} \mathrm{L}^{-1}$. Within this study, silver (Ag) and four carbon-supported Ag catalysts were synthesized by the $\gamma$-radiation method and their morphology and structure examined using transmission electron microscopy, $\mathrm{X}$-ray diffraction, and UV-Vis analysis. The nanocatalysts were tested for $\mathrm{Br}^{-}$sensing in aqueous media using cyclic voltammetry. All five $\mathrm{Ag}$ materials exhibited electroactivity for sensing of $\mathrm{Br}^{-}$ions, with pure $\mathrm{Ag}$ catalyst giving the best response to $\mathrm{Br}^{-}$ions presence in terms of the lowest limit of detection. Sensing of bromides was also explored in tap water after addition of bromides suggesting that herein prepared catalysts could be used for bromides detection in real samples. Furthermore, sensing of other halogen ions, namely, chlorides and iodides, was examined, and response due to chloride presence was recorded.

\section{Introduction}

According to the UN-Water Global Analysis and Assessment of Sanitation and Drinking Water (GLAAS) 2017 report, nearly two billion people use drinking water from sources polluted with faeces with over 500,000 diarrhoeal deaths per year. Ozone is a powerful disinfectant which can disarm even those resilient pathogenic microorganisms that common disinfectants such as chlorine and chlorine dioxide cannot. Still, high ozone exposure is necessary to neutralize these microorganisms, resulting in generation of undesirable disinfection by-products [1]. Thus, during ozonation of bromide $\left(\mathrm{Br}^{-}\right)$-containing waters, different bromoorganic by-products are generated in the reaction of hypobromous acid (product of the reaction of $\mathrm{Br}^{-}$and $\mathrm{O}_{3}$ ) with natural organic matter. Concentrations of these bromoorganic compounds are typically far below the drinking water standards. However, the main by-product of concern is bromate $\left(\mathrm{BrO}_{3}{ }^{-}\right)$, generated by the oxidation of bromide by both $\mathrm{O}_{3}$ and $\mathrm{OH}^{*}$, including several pathways and up to six oxidation states of bromine, Figure 1.

Bromate, unlike many other organic by-products, is not degraded in biological filters applied upon the ozonation process. Bromate is known to be the genotoxic carcinogen inducing, for instance, renal cell tumor in rats. It is believed that bromate toxic effects arise from the elevated levels of lipid peroxides (LPO) or from oxygen radicals formed from LPO and to induce DNA damage.

Thereafter, monitoring the level of halogen ions in water is nowadays of great importance for the protection of human health. Methods so far used or suggested for the detection of bromide and other halogens in water include neutron activation analysis, inductively coupled plasma-mass spectrometry, ion and liquid chromatography, and fluorescence spectroscopy [2-7]. These techniques often require complex procedures and expensive equipment.

On the other hand, electrochemical methods for detection of halogen ions offer benefits of low cost, simplicity, and 


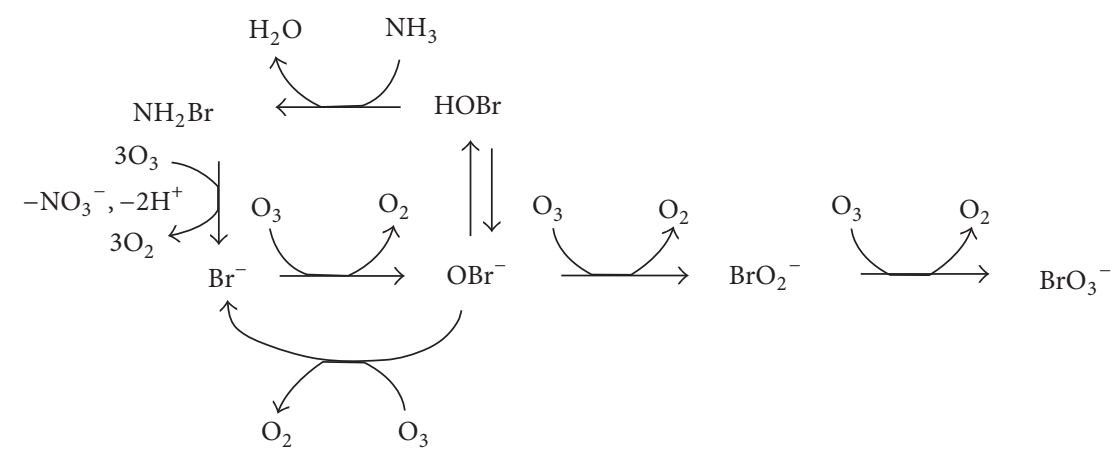

(a)

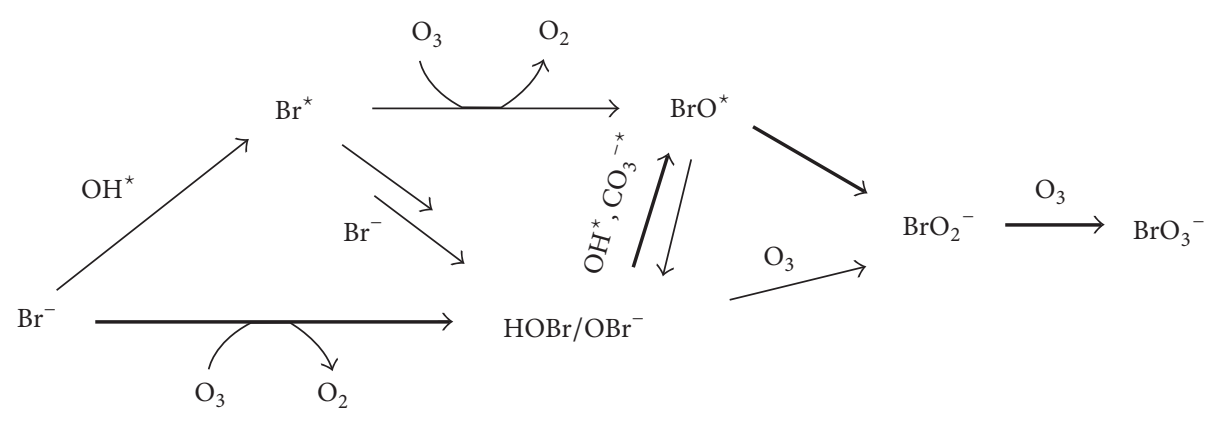

(b)

FIgure 1: Possible pathways of bromate formation during ozonation of bromide-containing waters: oxidation with (a) $\mathrm{O}_{3}$ and (b) $\mathrm{OH}^{\bullet}[1]$. $^{\circ}$

rapidity [8-11]. Silver (Ag) and Ag-based materials have been investigated as sensing electrode for these purposes $[8,12,13]$. $\mathrm{Ag}$ nanoparticles (NPs) can be synthesized in a variety of ways, with the most frequently employed being chemicalreduction methods. These methods involve reduction of $\mathrm{Ag}^{+}$ ions in aqueous solution using different reducing agents that can be toxic or non-environmentally friendly and the procedure comprises several time-consuming steps, including addition of reducing agent in the solution, filtering, washing, and drying.

Radiation methods of synthesis have several advantages over the other methods: rapidity, low operational costs, no reducing agent required, easier control of the synthesis parameters, absence of unnecessary synthesis products, convenience for large scale use, and environmental friendliness. A major advantage of the radiation synthesis of metal NPs is a homogenous reduction of metal ions throughout the solution. Radiation methods have already been used for preparation of Ag NPs for biomedical applications. In this method, $\mathrm{Ag}^{+}$ions were reduced by radiolytic products of water, where polymers, such as the poly(vinyl alcohol) and the chitosan, act as stabilizers for controlling the size of Ag NPs [14]. We have for the first time synthesized Ag NPs by $\gamma$-radiation method and investigated them as electrocatalysts for the oxygen reduction and borohydride oxidation reactions [15]. With respect to that research, this paper investigates similarly prepared Ag NPs with a focus on a different application.

The goal of this research is to investigate the potential application of Ag nanocatalysts, synthesized by the $\gamma$ radiation method, as electrode materials for detection of the halogen ions $\left(\mathrm{Br}^{-}, \mathrm{Cl}^{-}\right.$, and $\left.\mathrm{I}^{-}\right)$. As mentioned above, the radiation method, used in this work, enables direct preparation of the sensing electrode in a simple and a much faster way than a conventional approach, avoiding filtering, washing, and drying steps. The polymer used for controlling the Ag NPs size during the radiation procedure (synthesis of the Ag NPs) can later be used as the active material binder. Thus, in our approach, the Ag NP ink was prepared from the precursor in one-step radiation process. Prepared Ag NPs electrocatalysts were tested for detection of bromides, chlorides, and iodides using cyclic voltammetry.

\section{Experimental}

2.1. Materials. Poly(vinyl alcohol) (PVA) with mean molecular weight $M_{w}$ of $72 \mathrm{kDa}$ (degree of hydrolysis of $99 \%$ ), silver nitrate $\left(\mathrm{AgNO}_{3}\right)$, glutaraldehyde (GA, 25 wt. \% aqueous solution), and 2-propanol $\left(\left(\mathrm{CH}_{3}\right)_{2} \mathrm{CHOH}\right)$ were purchased from Merck, while argon gas was obtained from Messer Tehnogas, Serbia. The medium molecular weight chitosan (75-85\% degree of deacetylation, $M_{w}$ from 190 to $310 \mathrm{kDa}$ ) and potassium sulfate $\left(\mathrm{K}_{2} \mathrm{SO} 4\right)$, bromide $(\mathrm{KBr})$, chloride $(\mathrm{KCl})$, and iodide (KI) were supplied by Sigma-Aldrich. Carbon black, Vulcan XC 72R, was produced by Cabot Co. The chemicals were used as received, without additional purification. Water from Millipore Milli-Q system was used in all experiments.

2.2. Electrocatalyst Preparation. Both types of Ag NPs, nonsupported and supported on the carbon substrate $(\mathrm{Ag} / \mathrm{C})$, were synthesized by the $\gamma$-radiation reduction method using 


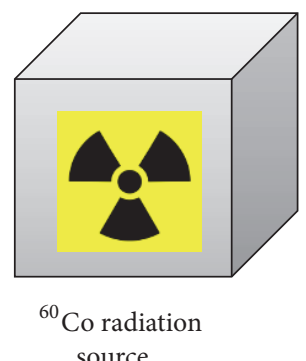

source

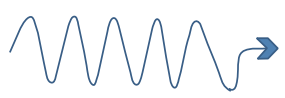

Gamma radiation
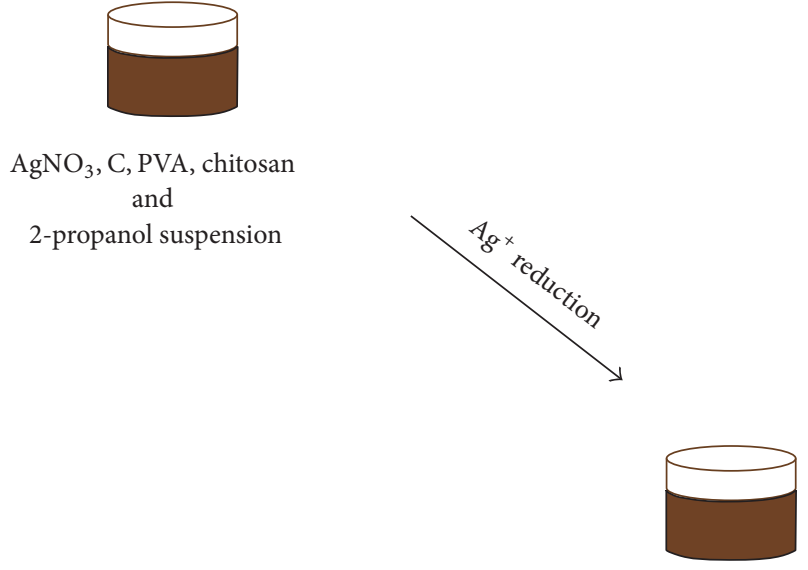

$\mathrm{Ag} / \mathrm{C}$ colloid suspension

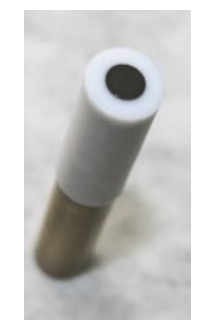

Sensing electrode

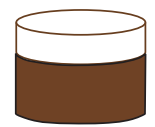

Catalyst

suspension

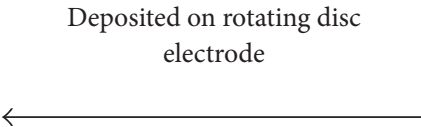
in the authors' previous paper [15]. In brief, five aqueous solutions containing polymer (weight ratio of PVA to CS was 3:1), $\mathrm{AgNO}_{3}$, and $\left(\mathrm{CH}_{3}\right)_{2} \mathrm{CHOH}$ were prepared. All solutions had constant concentration of $\mathrm{AgNO}_{3}(0.4 \mathrm{M})$ and $\left(\mathrm{CH}_{3}\right)_{2} \mathrm{CHOH}(0.2 \mathrm{M})$, while concentration of polymer varied $(2,4$, and 6 wt.\%). Different amounts of Vulcan XC $72 \mathrm{R}$ were added to the four out of five solutions (Table 1) and the obtained dispersions were homogenized ultrasonically. Four dispersions and one solution without carbon were then deaerated with argon for $20 \mathrm{~min}$ in an air-tight glass vessel, and after that they were exposed to $\gamma$-rays $\left({ }^{60} \mathrm{Co}\right.$ source) at the temperature of $22^{\circ} \mathrm{C}$. The absorbed dose and the dose rate were $700 \mathrm{kGy}$ and $12 \mathrm{kGy} \mathrm{h}^{-1}$, respectively.

2.3. Characterization. Transmission electron microscopy (TEM) analysis was done using the JEOL JEM-1400Plus device, while the X-ray diffraction (XRD) analysis was done using Bruker D8 Advance Diffractometer $\left(\mathrm{Cu} \mathrm{K} \mathrm{K}_{\alpha 1}\right.$ radiation, $\lambda=0.1541 \mathrm{~nm}$ ). Optical characterization of the as-prepared Ag NPs was carried out using Thermo Scientific Evolution $600 \mathrm{UV}$-Vis spectrophotometer in the $300-800 \mathrm{~nm}$ wavelength range.
TABLE 1: Weight ratios of Ag, C, and polymer in the initial colloid suspensions.

\begin{tabular}{lc}
\hline Colloid suspension number & Ag: C: Polymer \\
\hline 101 & $1: 0: 1$ \\
214 & $1: 0.4: 1$ \\
116 & $1: 1: 2$ \\
114 & $1: 1: 1$ \\
112 & $1: 1: 0.5$ \\
\hline
\end{tabular}

2.4. Electrochemical Study. The working electrode was prepared as follows: $0.5 \mathrm{wt}$.\% GA solution was added to each of the obtained catalyst dispersions (molar ratio of GA to polymer was $8.2: 1$ ), after which the dispersions were diluted and the appropriate volume of $1 \mathrm{M} \mathrm{HCl}$ was added, in order to obtain $\mathrm{HCl}$ concentration of $0.1 \mathrm{M}$ in the final dispersion. $10 \mu \mathrm{L}$ of this dispersion was dropped on the glassy carbon electrode (GCE, $0.196 \mathrm{~cm}^{2}$, Pine Instruments Co.) resulting in $\mathrm{Ag}$ loading on the electrode of $20 \mu \mathrm{g} \mathrm{cm}^{-2}$. Crosslinking of the polymer with $\mathrm{GA}$ was achieved by $\mathrm{HCl}$ during the drying under the nitrogen atmosphere, and the gel that was formed acted as a binder. In order to wash out the $\mathrm{Cl}^{-}$ions from the 


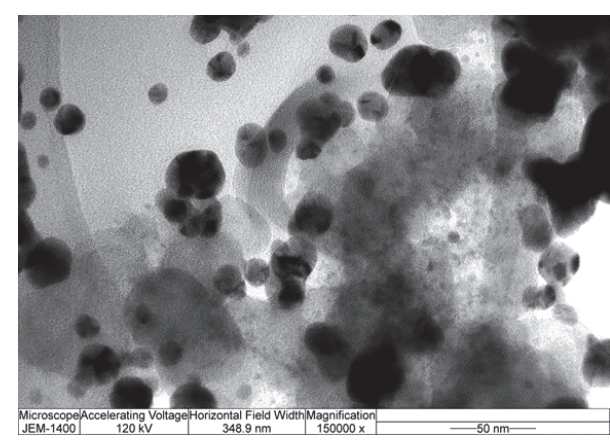

(a)

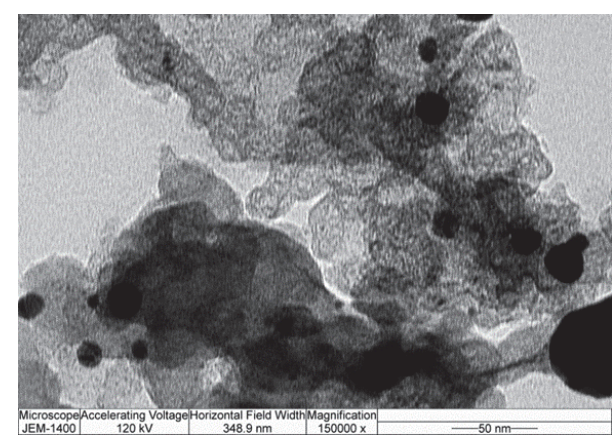

(b)

FIGURE 3: Representative TEM micrographs of Ag/C catalyst obtained from the colloid suspensions 214 (a) and 116 (b).

electrodes, they were immersed for 10 minutes in deionized water.

Electrochemical characterization of the five Ag catalysts was done by cyclic voltammetry (CV) using a Gamry PCI4/750 potentiostat/galvanostat. For all electrochemical measurements within this study, catalyst-coated GCE served as working electrode; Pt foil was employed as the counter electrode and a saturated calomel electrode (SCE, Radiometer Analytical) as reference. All potentials are reported relative to the SCE. CVs were recorded in $0.1 \mathrm{M} \mathrm{K}_{2} \mathrm{SO}_{4}$ solution as supporting electrolyte. $\mathrm{Br}^{-}$ions detection was done by $\mathrm{CV}$ measurements in bromide solution in $0.1 \mathrm{M} \mathrm{K}_{2} \mathrm{SO}_{4}$ in the potential range from $-0.9 \mathrm{~V}$ to $0.5 \mathrm{~V}$ at scan rate of $100 \mathrm{mVs}^{-1} \cdot \mathrm{Cl}^{-}$and $\mathrm{I}^{-}$ions detection was assessed under the same experimental conditions.

\section{Results and Discussion}

3.1. Characterization of the $\mathrm{Ag}$ and $\mathrm{Ag} / \mathrm{C}$ Catalysts. The radiation-induced reduction of $\mathrm{Ag}^{+}$starts with the radiolysis of water and formation of hydrated electrons, hydrogen $\left(\mathrm{H}^{\bullet}\right)$ and hydroxyl radicals $\left(\mathrm{OH}^{\circ}\right)$. Hydrated electrons and $\mathrm{H}^{\bullet}$ radicals reduce $\mathrm{Ag}^{+}$to $\mathrm{Ag}^{0}$, which further dimerize when they encounter or associate with $\mathrm{Ag}^{+}$and progressively grow yielding the formation of metal clusters and particles. The detailed mechanism of Ag NP formation by radiation methods has been explained by Belloni [16]. Since the $\mathrm{OH}^{\bullet}$ radicals can oxidize the metal atoms into a higher oxidation state and thus counterbalance the reduction, $\left(\mathrm{CH}_{3}\right)_{2} \mathrm{CHOH}$ is used as a scavenger to convert them to 2-propanol radicals $\left({ }^{\bullet}\left(\mathrm{CH}_{3}\right)_{2} \mathrm{CHOH}\right)$, which further act as strong reducing species. It should be mentioned that the Ag NP dispersions are stable at room temperature for several days. However, at lower temperatures (around $7^{\circ} \mathrm{C}$ ), the pure Ag dispersion (101) can withstand more than a year without precipitation of Ag.

The detailed XRD and TEM analysis of the Ag NPs obtained by the $\gamma$-radiation method was reported in our previous publication [15], in which different $\mathrm{Ag} / \mathrm{C}$ samples were investigated as electrocatalysts for the oxygen reduction and borohydride oxidation reaction. In brief, TEM analysis of $\mathrm{Ag} / \mathrm{C}$ samples has shown that an average particle size of $\mathrm{Ag} \mathrm{NPs}$ is between $14 \mathrm{~nm}$ and $18 \mathrm{~nm}$ and that there is no big difference in average particle diameters between samples. The TEM micrographs of $\mathrm{Ag}$ samples obtained from the colloid suspensions 214 and 116 are presented in Figure 3. It was observed that number of smaller particles is notably higher than the number of larger ones. Furthermore, bimodal particle size distributions are seen for all studied electrocatalysts, most likely due to the high concentration of Ag compared to that of stabilizer and possibly due to the interaction of $\mathrm{Ag}$ NPs with $\mathrm{C}$ affecting the NPs stabilization [15]. XRD analysis (not shown) revealed the formation of face centered cubic (FCC) crystal structure of bulk metallic Ag in case of $\mathrm{Ag}, \mathrm{Ag}_{214} / \mathrm{C}, \mathrm{Ag}_{114} / \mathrm{C}$, and $\mathrm{Ag}_{116} / \mathrm{C}$, and mixture of metallic Ag and $\mathrm{Ag}$ oxide NPs in case of $\mathrm{Ag}_{112} / \mathrm{C}$ [15]. It was observed that higher amount of $\mathrm{C}$ and $\mathrm{Ag}$ : polymer ratio different than 1:1 led to disturbance of the crystal structure. Additionally, crystallite size, texture coefficient $\left(C_{\mathrm{txt}}\right)$, interplanar spacing between atoms $(d)$, and lattice parameter $(a)$ of $\mathrm{Ag}, \mathrm{Ag}_{214} / \mathrm{C}, \mathrm{Ag}_{114} / \mathrm{C}$, and $\mathrm{Ag}_{116} / \mathrm{C}$ were determined from the XRD pattern data. Thus, crystallite size of the samples determined by XRD was found to be from $14.6 \mathrm{~nm}$ to $20.0 \mathrm{~nm}$, which is in good agreement with the crystallite size evaluated by TEM. Obtained values of $C_{\mathrm{txt}}$ for (111), (200), (220), and (311) planes were evaluated to be in the range from 0.55 to 1.05 , with these values indicating planes with no preferential growth orientation. $\Delta d / d_{0}{ }^{(111)}$ ranging from -0.0001 to -0.0018 and $\Delta a / a_{0}{ }^{\text {sr }}$ values ranging from -0.0008 to -0.0022 confirmed formation of bulk FCC Ag structure. The lattice parameters were found to be lower than the bulk lattice constant indicating presence of strain and stress that could further lead to the change in the bond length and to the change of energy levels of the bonding electrons $[15,17]$.

$\mathrm{UV}$-Vis spectrum of $\mathrm{Ag} /$ polymer $\left(\mathrm{Ag}_{101}\right)$ colloid is shown in Figure 4 (solid line). For nanoparticles smaller than $20 \mathrm{~nm}$, the average radius of the nanoparticles can be determined by the full width at half maximum (FWHM) of their corresponding SPR band using the relation

$$
r_{\exp }=\frac{V_{f}}{\Delta \omega_{1 / 2}},
$$

where $r_{\exp }$ is the particle radius, $V_{f}$ is the Fermi velocity of the metal, and $\Delta \omega_{1 / 2}$ is the FWHM for the SPR band in 
TABLE 2: Ag NP sizes evaluated using UV-Vis spectroscopy and using Mie's theory.

\begin{tabular}{lcccc}
\hline \multirow{2}{*}{ Sample } & \multirow{2}{*}{ FWHM $(\Delta \lambda)(\mathrm{nm})$} & \multicolumn{2}{c}{ Average diameter $(\mathrm{nm})$} & Surface $\operatorname{area}\left(\mathrm{m}^{2} \mathrm{~g}^{-1}\right)$ \\
\hline 101 & 97.51 & UV/Vis & 16.6 & 40.2 \\
214 & 110.50 & 16.3 & 17.7 & 35.1 \\
\hline
\end{tabular}

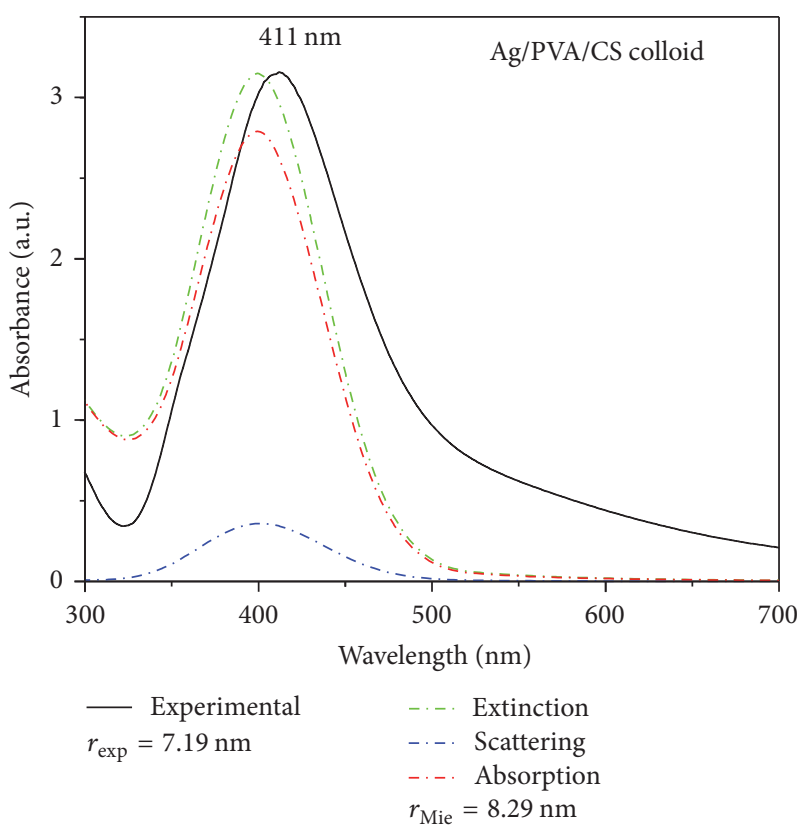

FIGURE 4: UV-Vis absorption spectra of $\mathrm{Ag}_{101}$ colloid suspension. The solid line corresponds to the experimental spectrum and the dashed lines correspond to the calculated simulation spectra using the Mie model.

units of angular frequency [18]. The calculated experimental average particle diameters of as-prepared Ag NPs are given in Table 2. Taking into account the calculated values for the Ag NPs radii, the corresponding theoretical optical extinction spectra are simulated using a computer program "MiePlot v.3.4" [19], whose algorithm is based on the Mie's theory (Figure 4, dashed lines) [20].

The calculated values of average $\mathrm{Ag}_{101}$ NPs diameters obtained by the fitting to experimental spectra are given in Table 2. Size of Ag NPs in the colloid sample $\mathrm{Ag}_{214}$ has been determined as well (Table 2), while this was not possible for other dispersions due to a large amount of carbon. As it can be seen in Table 2, the average sizes of Ag NPs in the colloid samples 101 and 214 determined by UV-Vis, XRD, and TEM analysis are in good correlation. Considering the experimentally determined diameters and that Ag NPs are ideal spheres, the surface area (SA) of Ag NPs was calculated using the equation $\mathrm{SA}=6 / \rho D$, where $\rho$ is the theoretical density of $\mathrm{Ag}\left(10.5 \mathrm{~g} \mathrm{~cm}^{-3}\right)$ and $D$ is the diameter of Ag NPs.

Electrochemical characterization was done in $0.1 \mathrm{M}$ $\mathrm{K}_{2} \mathrm{SO}_{4}$ at scan rate of $100 \mathrm{mV} \mathrm{s}^{-1}$. Figure 5(a) illustrates the electrochemical characterization of pure $\mathrm{Ag}$ catalyst where $\mathrm{Ag}$ oxidation to $\mathrm{Ag}_{2} \mathrm{O}$ is observed as peak at ca. $0.15 \mathrm{~V}$. On the cathodic scan, pronounced oxide reduction peak could be seen at ca. $-0.05 \mathrm{~V}$ in agreement with the literature data [8]. Qualitatively similar CVs were obtained for other Ag electrocatalysts; namely, distinctly defined Ag oxidation peaks were observed at potentials above $0.25 \mathrm{~V}$ with corresponding oxides reduction peak in the potential range from $0.15 \mathrm{~V}$ to $0 \mathrm{~V}$ (Figure 5(a) shows $\mathrm{CV}$ of $\mathrm{Ag}_{214}$ ). Charge under the reduction peaks was used to evaluate the electrochemical surface area (ECSA), assuming that charge associated with one Ag oxide monolayer is $2.10 \mathrm{C} \mathrm{m}^{-2}$ [21]. These ECSA were used to calculate specific current densities.

3.2. Sensing of Bromides. Subsequently, possibility of using prepared $\mathrm{Ag}$ and $\mathrm{Ag} / \mathrm{C}$ catalysts for electroanalytical sensing of bromides was examined. Therefore, $\mathrm{CVs}$ of all five $\mathrm{Ag}$ materials were recorded in $0.25 \mathrm{mM} \mathrm{KBr}+0.1 \mathrm{M} \mathrm{K}_{2} \mathrm{SO}_{4}$ in the potential range from $-1 \mathrm{~V}$ to $0.5 \mathrm{~V}$ at scan rate of $100 \mathrm{mVs}^{-1}$ (Figure 5(b)). All five catalysts gave well defined oxidation peak in the potential range of $0-0.2 \mathrm{~V}$ evidencing formation of silver bromide $(\mathrm{AgBr})$. Formed $\mathrm{AgBr}$ was reduced on the reverse scan with the reduction peak seen at potentials lower than ca. $-0.2 \mathrm{~V}$. The principle of bromide (as well as other halogen ions) sensing by Ag electrodes can be described by [26]

$$
\mathrm{Ag}+\mathrm{Br}^{-} \longrightarrow \mathrm{AgBr}+\mathrm{e}^{-}
$$

Pure Ag catalyst was observed to give the highest peak current density (j) value $\left(1.19 \mathrm{~mA} \mathrm{~cm}^{-2}\right)$, followed by $\mathrm{Ag}_{214} / \mathrm{C}\left(0.59 \mathrm{~mA} \mathrm{~cm}^{-2}\right), \mathrm{Ag}_{114} / \mathrm{C}\left(0.36 \mathrm{~mA} \mathrm{~cm}^{-2}\right), \mathrm{Ag}_{116} / \mathrm{C}$ $\left(0.23 \mathrm{~mA} \mathrm{~cm}^{-2}\right)$, and $\mathrm{Ag}_{112} / \mathrm{C}\left(0.07 \mathrm{~mA} \mathrm{~cm}^{-2}\right)$. It is worth noting that these peak current/current density values are one order of magnitude higher than the current values obtained by different Ag NPs reported in the literature [8]. Although metal nanocatalysts are usually supported on carbon materials in order to increase their active surface area and to improve their utilization, herein nonsupported Ag NP outperformed the supported ones. Differences in the activity of the five studied electrocatalysts for $\mathrm{Br}^{-}$sensing can be attributed to the differences in their particle size, surface structure, and $\mathrm{C}$ and polymer percentage. The highest peak current density observed for $\mathrm{Ag}$ and then $\mathrm{Ag}_{214} / \mathrm{C}$ can be correlated with the smaller particle size of these two electrocatalysts and consequently to their higher specific surface area. Furthermore, it can be observed that the lower peak current densities are observed for electrocatalysts containing higher percentage of $\mathrm{C}\left(\mathrm{Ag}_{114} / \mathrm{C}, \mathrm{Ag}_{116} / \mathrm{C}\right.$, and $\mathrm{Ag}_{112} / \mathrm{C}$ ), suggesting that $\mathrm{C}$ hinders access of $\mathrm{Br}^{-}$ions to Ag surface. Surface structure also plays significant role in the catalytic activity of Ag-based materials as it was shown 


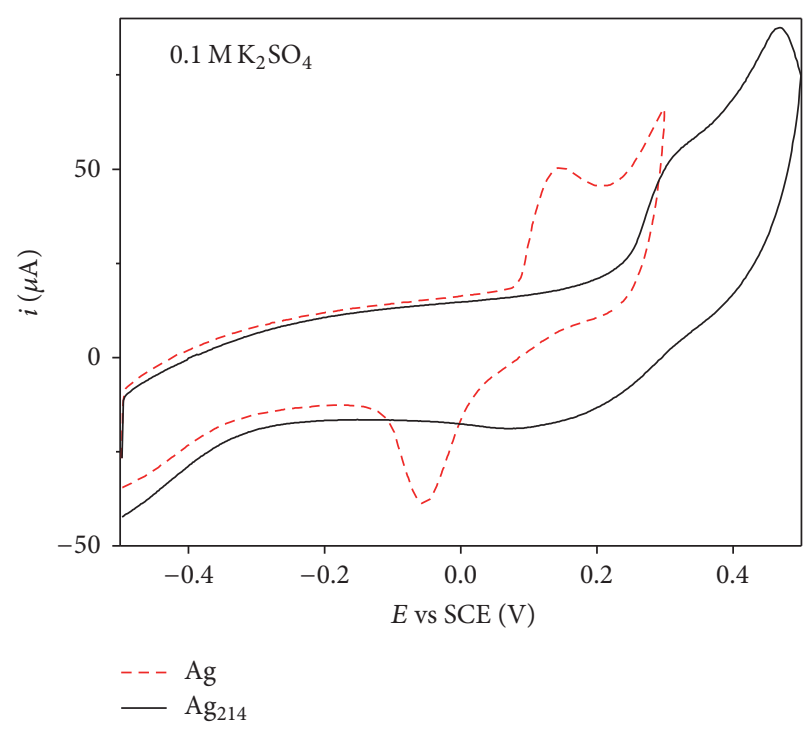

(a)

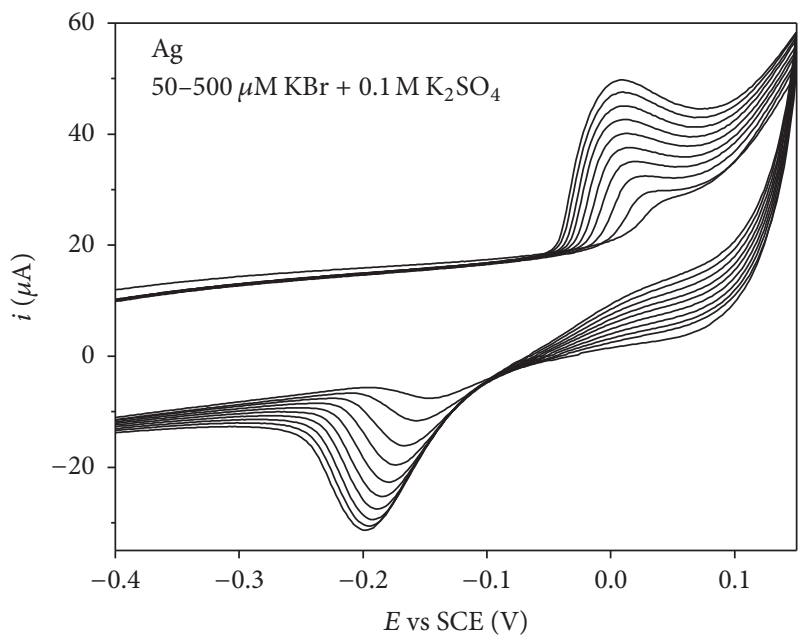

(c)

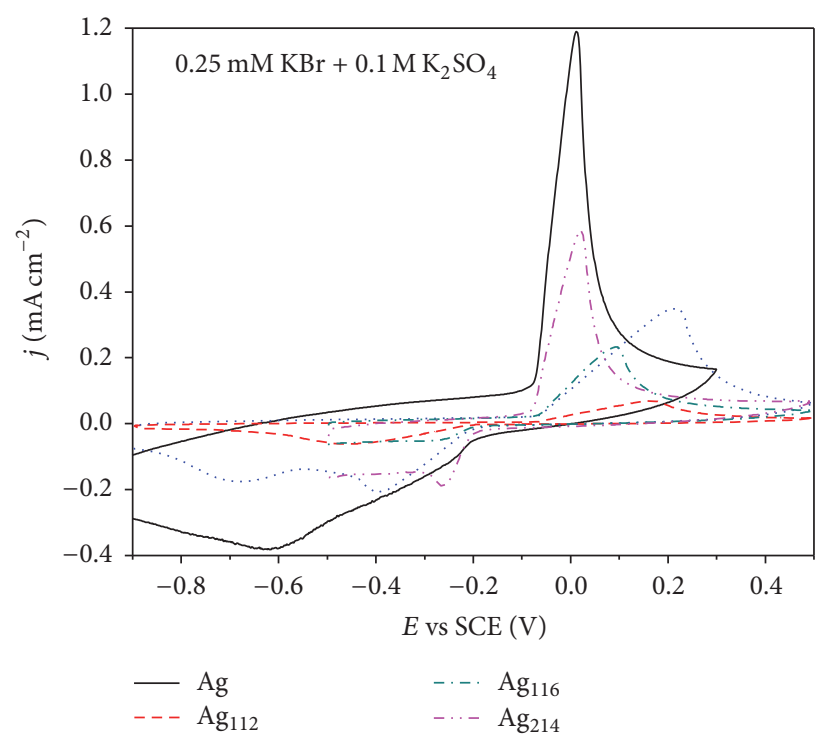

(b)

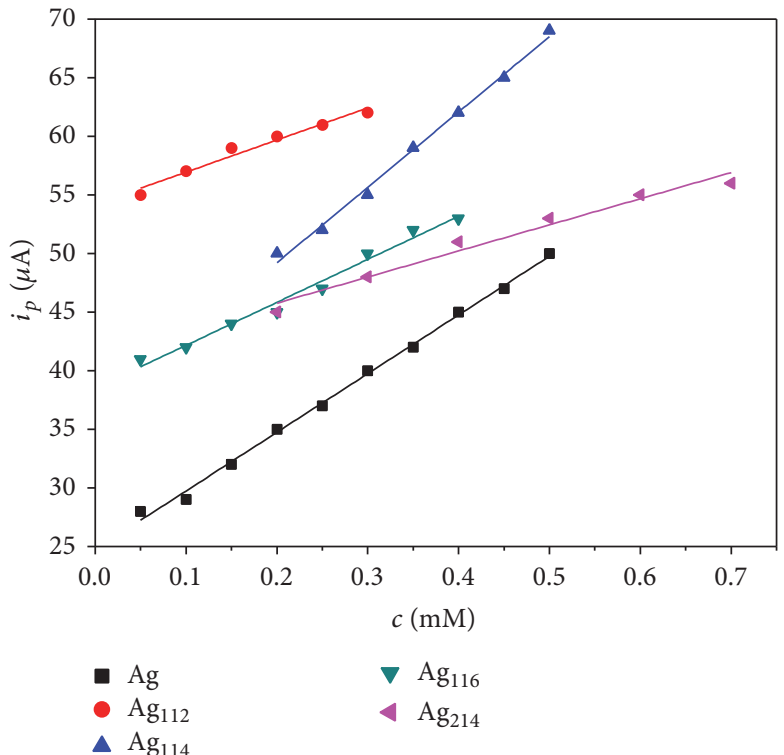

(d)

Figure 5: (a) CVs of $\mathrm{Ag}$ and $\mathrm{Ag}_{214} / \mathrm{C}$ catalyst in $0.1 \mathrm{M} \mathrm{K}_{2} \mathrm{SO}_{4}$ solution at scan rate of $100 \mathrm{mV} \mathrm{s}^{-1}$; (b) CVs of all five catalysts in $0.25 \mathrm{mM} \mathrm{KBr}$ $+0.1 \mathrm{M} \mathrm{K}_{2} \mathrm{SO}_{4}$ at scan rate of $100 \mathrm{mVs}^{-1}$; (c) CVs of $\mathrm{Ag}$ catalyst in $0.1 \mathrm{M} \mathrm{K}_{2} \mathrm{SO}_{4}$ as supporting electrolyte with increasing $\mathrm{KBr}$ concentration from 0.05 to $0.5 \mathrm{mM}$ at scan rate of $10 \mathrm{mVs}^{-1}$; (d) oxidation peak current as a function of $\mathrm{KBr}$ concentration for all five catalysts.

that different Ag surface planes catalyze electrochemical reactions at different rate [15].

Subsequently, CVs of all five Ag catalysts were recorded in $0.1 \mathrm{M} \mathrm{K}_{2} \mathrm{SO}_{4}$ solution increasing the $\mathrm{KBr}$ concentration with $50 \mu \mathrm{M}$ additions of $\mathrm{KBr}$ to $0.1 \mathrm{M} \mathrm{K}_{2} \mathrm{SO}_{4}$, except in the case of $\mathrm{Ag}_{214} / \mathrm{C}$ catalyst where $100 \mu \mathrm{M}$ additions were made (Figure 5(c) shows the corresponding CVs of pure $\mathrm{Ag}$ ). Increase of peak current $\left(i_{p}\right)$ could be observed with increase of $\mathrm{KBr}$ concentration $(c)$, with $i_{p}$ versus $c$ dependence resulting in straight lines with correlation coefficients in the $0.96008-0.99648$ range, Figure 5(d).
The limit of detection (LOD) of bromide at $\mathrm{Ag}$ and $\mathrm{Ag} / \mathrm{C}$ catalysts was evaluated using the 3 -sigma method

$$
\mathrm{LOD}=\frac{3 \sigma}{b}
$$

where $\sigma$ is the standard deviation of the $y$ coordinates from the line of best fit and $b$ the slope of the same line. The lowest limit of bromides detection of $18 \mu \mathrm{M}$ was evaluated with pure Ag catalyst. $\mathrm{Ag}_{114} / \mathrm{C}$ and $\mathrm{Ag}_{116} / \mathrm{C}$ gave similar LODs of 36 and $40 \mu \mathrm{M}$, respectively, followed by $\mathrm{Ag}_{112} / \mathrm{C}$ that gave LOD of $53 \mu \mathrm{M}$, while the highest LOD of $102 \mu \mathrm{M}$ was obtained 
TABLE 3: Comparison of performance of different electrodes for bromide sensing.

\begin{tabular}{|c|c|c|c|c|}
\hline Catalyst & Electrolyte & Peak current/ $\mu \mathrm{A}$ & Peak potential/V & LOD \\
\hline Ag (present catalyst) & $0.25 \mathrm{mM} \mathrm{KBr}+0.1 \mathrm{M} \mathrm{K}_{2} \mathrm{SO}_{4}$ & 310 & 0.01 & $18 \mu \mathrm{M}$ \\
\hline $\mathrm{Ag}_{112} / \mathrm{C}$ (present catalyst) & $0.25 \mathrm{mM} \mathrm{KBr}+0.1 \mathrm{M} \mathrm{K}_{2} \mathrm{SO}_{4}$ & 446 & 0.16 & $53 \mu \mathrm{M}$ \\
\hline $\mathrm{Ag}_{114} / \mathrm{C}$ (present catalyst) & $0.25 \mathrm{mM} \mathrm{KBr}+0.1 \mathrm{M} \mathrm{K}_{2} \mathrm{SO}_{4}$ & 704 & 0.21 & $36 \mu \mathrm{M}$ \\
\hline $\mathrm{Ag}_{116} / \mathrm{C}$ (present catalyst) & $0.25 \mathrm{mM} \mathrm{KBr}+0.1 \mathrm{M} \mathrm{K}_{2} \mathrm{SO}_{4}$ & 390 & 0.09 & $40 \mu \mathrm{M}$ \\
\hline $\mathrm{Ag}_{214} / \mathrm{C}$ (present catalyst) & $0.25 \mathrm{mM} \mathrm{KBr}+0.1 \mathrm{M} \mathrm{K}_{2} \mathrm{SO}_{4}$ & 317 & 0.02 & $102 \mu \mathrm{M}$ \\
\hline AgNP-GC-BPPG ${ }^{*}[8]$ & $0.16 \mathrm{mM} \mathrm{KBr}+0.1 \mathrm{M} \mathrm{K}_{2} \mathrm{SO}_{4}$ & $\approx 15$ & $\approx 0.14$ & $3 \mu \mathrm{A}$ \\
\hline $\mathrm{Ag} / \mathrm{Au} / \mathrm{PdNP}-\mathrm{GC}-\mathrm{BPPG}^{*}[8]$ & $0.16 \mathrm{mM} \mathrm{KBr}+0.1 \mathrm{M} \mathrm{K}_{2} \mathrm{SO}_{4}$ & $\approx 25$ & $\approx 0.18$ & I \\
\hline Ag electrode [22] & $\begin{array}{c}2 \mathrm{mM} \text { bromide ions in } \mathrm{pH} 7 \\
\text { phosphate buffer }\end{array}$ & l & $\approx 0$ & $5 \mathrm{mM}$ \\
\hline $\mathrm{Hg}$ (II) complex ${ }^{* *}[23]$ & l & l & l & $4 \mu \mathrm{M}$ \\
\hline $\begin{array}{l}\text { MWNTs-chitosan modified } \\
\text { GCE }^{* * *}[24]\end{array}$ & $\begin{array}{c}7.2 \cdot 10^{-6} \mathrm{gmL}^{-1} \text { bromide ions in } \\
\mathrm{pH} 1.8 \mathrm{H}_{2} \mathrm{SO}_{4} \text { solution }\end{array}$ & $\approx 78$ & 0.71 & $9.6 \cdot 10^{-8} \mathrm{~g} \mathrm{ml}^{-1}$ \\
\hline GCM-Ag/MWCNT/GC ${ }^{* * * *}[25]$ & $\begin{array}{c}5 \mathrm{mM} \text { bromide ions in } 0.1 \mathrm{M} \\
\text { phosphate buffer }\end{array}$ & $\approx 750$ & $\approx 0.1$ & $22 \mu \mathrm{M}$ \\
\hline
\end{tabular}

${ }^{*}$ NP-GC-BPPG: nanoparticles on glassy carbon spherical powder with basal plane pyrolytic graphite electrode, ${ }^{* *} \mathrm{Hg}(\mathrm{II})$ complex containing carbon paste electrode, ${ }^{* * *}$ MWNT: multiwall carbon nanotubes, GCE: glassy carbon electrode, ${ }^{* * * *}$ GCM: glassy carbon metal, and MWCNT: multiwall carbon nanotube.

using $\mathrm{Ag}_{214} / \mathrm{C}$, Table 3. Good reproducibility of the catalysts performance was observed with standard deviation (10 measurements) in the $4.8-8.3 \%$ range. It should be noted that higher sensitivity with Ag electrodes studied herein could be obtained using more sensitive electroanalytical methods (such as square wave voltammetry, differential pulse voltammetry, and chronoamperometry) and with optimisation of operational parameters. Still, the LOD value obtained at pure $\mathrm{Ag}$ catalyst was somewhat higher or comparable with LODs obtained using different Ag-based catalysts for bromide sensing reported in the literature (LODs in 1.2-22 $\mu \mathrm{M}$ range) [2329]. For example, Compton et al. reported LOD for bromides of $3 \mu \mathrm{M}$ at AgNPs-GC-epoxy composite electrode and of $22 \mu \mathrm{M}$ at GCM-Ag/MWCNT/GCE (Glassy Carbon Metal, Multi Wall Carbon Nanotube, Glassy Carbon Electrode) [8, 25]. Furthermore, Binghui et al. reported LODs for bromide between 0.023 and $2.0 \mu \mathrm{g} \mathrm{L}^{-1}$ using ion chromatography [6].

3.3. Sensing of Chlorides and Iodides. As pure Ag catalyst gave the lowest LOD for bromides, it was further tested for sensing of other halogen ions, namely, chlorides and iodides. For that purpose, CV of pure Ag catalyst was recorded in $0.25 \mathrm{mM}$ $\mathrm{KCl}$ solution under the same experimental conditions as in the case of bromides detection, Figure 6. A clear oxidation peak evidencing formation of silver chloride $(\mathrm{AgCl})$ could be seen at ca. $0.15 \mathrm{~V}$, indicating potential application of $\mathrm{Ag}$ catalyst for chloride sensing. Furthermore, CVs of Ag catalyst were recorded increasing the $\mathrm{KCl}$ concentration from 50 to $500 \mu \mathrm{M}$. Dependence of the oxidation peak current on $\mathrm{KCl}$ concentration resulted in a straight line with correlation factor of 0.98678 , and data from that line were used for evaluation of the limit of chloride detection using Ag catalyst. Thus, LOD of chloride was determined to be $51.3 \mu \mathrm{M}$ with standard deviation (10 measurements) of 6.9\%. Sánchez-Polo et al. reported LOD for bromide and chloride ions of 3 and $1 \mu \mathrm{g} \mathrm{L}^{-1}$, respectively, by ion chromatography [30].

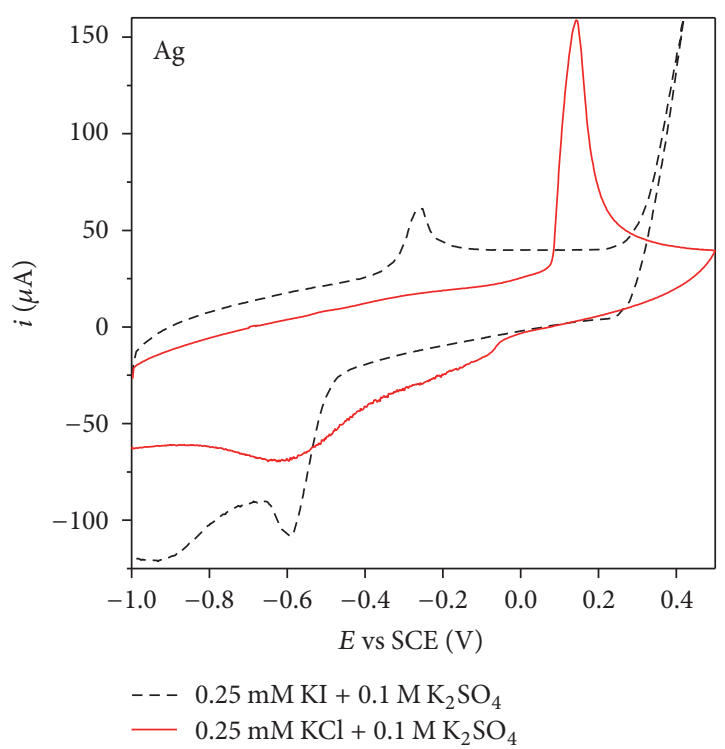

FIgUre 6: CVs of pure Ag catalyst in $0.25 \mathrm{mM} \mathrm{KI}(---)$ and $0.25 \mathrm{mM}$ $\mathrm{KCl}(-)$ in $0.1 \mathrm{M} \mathrm{K}_{2} \mathrm{SO}_{4}$ as supporting electrolyte recorded at scan rate of $100 \mathrm{mV} \mathrm{s}^{-1}$.

Contrary to CVs of Ag catalyst recorded in $0.25 \mathrm{mM} \mathrm{KBr}$ and $0.25 \mathrm{mM} \mathrm{KCl}$ solutions, where well defined oxidation peaks were observed, only a vague peak at ca. $-0.25 \mathrm{~V}$ could be seen at the CV recorded in $0.25 \mathrm{mM}$ KI solution. Increase of KI concentration in the 50 to $500 \mu \mathrm{M}$ range did not result in the noteworthy increase of the oxidation peak current. Thus, due to the poor signal, limit of iodide detection using $\mathrm{Ag}$ catalyst could not be determined.

3.4. Sensing of Bromides in Real Samples. Finally, possibility of using Ag catalyst for sensing of bromides in real sample was explored by recording CV of Ag catalyst in tap water 


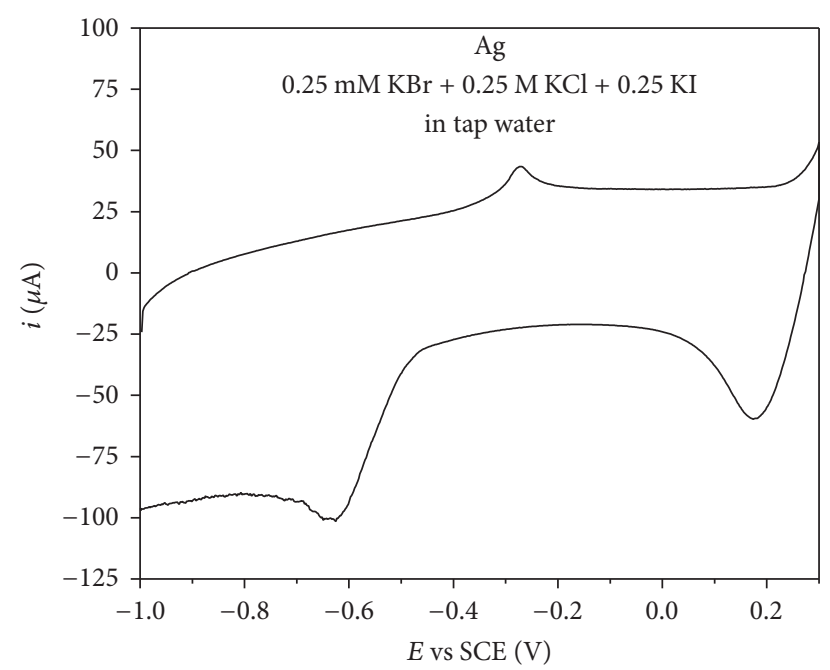

Figure 7: CV of Ag catalyst in $0.25 \mathrm{mM} \mathrm{KBr}+0.25 \mathrm{mM} \mathrm{KCl}+$ $0.25 \mathrm{mM} \mathrm{KI}$ in tap water recorded at scan rate of $100 \mathrm{mV} \mathrm{s}^{-1}$.

after addition of $0.25 \mathrm{mM} \mathrm{KBr}+0.25 \mathrm{mM} \mathrm{KCl}+0.25 \mathrm{mM}$ $\mathrm{KI}$ without any pretreatment of the sample. No peak was observed at $\mathrm{CV}$ recorded in tap water prior to halides addition. Conversely, two peaks could be observed, a peak at ca. $0.18 \mathrm{~V}$ corresponding to bromide presence and a peak at ca. $-0.6 \mathrm{~V}$ corresponding to chloride presence, Figure 7. Again, no peak due to presence of iodides could be seen. Clear separation of two peaks confirms that Ag could be used for bromides sensing in real samples in the presence of interferents as well.

The results indicate that $\mathrm{Ag}$ and $\mathrm{Ag} / \mathrm{C}$ catalysts prepared within this study could be used as sensing electrode materials for detection of different halogen ions, namely, $\mathrm{Br}^{-}$and $\mathrm{Cl}^{-}$ ions. Among studied catalysts, pure Ag NPs showed the best performance for halogen ions sensing.

\section{Conclusions}

Ag NPs and carbon-supported Ag NPs of ca. 14-18 nm diameter were prepared using $\gamma$-radiation method and evaluated as sensing electrodes for bromide detection. Limit of bromides detection was evaluated using the 3-sigma method. Pure Ag electrocatalyst gave the best results as evidenced by the lowest LOD of $18 \mu \mathrm{M}$. Furthermore, this catalyst was shown to be active for chloride detection as well. Finally, bromide sensing was assessed in real sample and the catalyst gave a clear response to bromides presence suggesting catalysts' potential application for sensing of bromides in real samples.

\section{Conflicts of Interest}

The authors declare that they have no conflicts of interest.

\section{Acknowledgments}

The authors would like to thank the Ministry of Education, Science and Technological Development of the Republic of
Serbia for support within projects OI-172043 (J. Milikić and B. Šljukić) and III-45005 (J. Krstić and Z. Kačarević-Popović). S. Miljanić and I. Stoševski acknowledge the support of NATO-Science for Peace and Security Programme through the project "DURAPEM-Novel Materials for Durable Proton Exchange Membrane Fuel Cells."

\section{References}

[1] U. Von Gunten, "Ozonation of drinking water: part II. Disinfection and by-product formation in presence of bromide, iodide or chlorine," Water Research, vol. 37, no. 7, pp. 1469-1487, 2003.

[2] K. Tagami and S. Uchida, "Concentrations of chlorine, bromine and iodine in Japanese rivers," Chemosphere, vol. 65, no. 11, pp. 2358-2365, 2006.

[3] K. Tagami, S. Uchida, I. Hirai, H. Tsukada, and H. Takeda, "Determination of chlorine, bromine and iodine in plant samples by inductively coupled plasma-mass spectrometry after leaching with tetramethyl ammonium hydroxide under a mild temperature condition," Analytica Chimica Acta, vol. 570, no. 1, pp. 88-92, 2006.

[4] L. Fu, C. Li, Y. Li, S. Chen, Y. Long, and R. Zeng, "Simultaneous determination of iodide and bromide using a novel LSPR fluorescent Ag nanocluster probe," Sensors and Actuators, B: Chemical, vol. 240, pp. 315-321, 2017.

[5] M. Takahashi, H. Kinoshita, M. Nishiguchi, and H. Nishio, "Bromide detection in blood using energy dispersive X-ray fluorescence; a chemical marker supportive of drowning in seawater," Legal Medicine, vol. 12, no. 3, pp. 132-136, 2010.

[6] Z. Binghui, Z. Zhixiong, and Y. Jing, "Ion chromatographic determination of trace iodate, chlorite, chlorate, bromide, bromate and nitrite in drinking water using suppressed conductivity detection and visible detection," Journal of Chromatography A, vol. 1118, no. 1, pp. 106-110, 2006.

[7] S. A. Cherstniakova, G. E. Garcia, J. Strong et al., "Rapid determination of $\mathrm{N}, \mathrm{N}$-diethyl-m-toluamide and permethrin in human plasma by gas chromatography-mass spectrometry and pyridostigmine bromide by high-performance liquid chromatography," Journal of Analytical Toxicology, vol. 30, no. 1, pp. 21-26, 2006.

[8] B. Šljukić, R. Baron, C. Salter, A. Crossley, and R. G. Compton, "Combinatorial electrochemistry using metal nanoparticles: From proof-of-concept to practical realisation for bromide detection," Analytica Chimica Acta, vol. 590, no. 1, pp. 67-73, 2007.

[9] S. Fierro, C. Comninellis, and Y. Einaga, "Simultaneous detection of iodine and iodide on boron doped diamond electrodes," Talanta, vol. 103, pp. 33-37, 2013.

[10] J.-F. Huang, "Silver UPD ultra-thin film modified nanoporous gold electrode with applications in the electrochemical detection of chloride," Talanta, vol. 77, no. 5, pp. 1694-1700, 2009.

[11] D. Kim and J. Chang, "Determination of stannous chloride and stannic bromide speciation in concentrated $\mathrm{Cl}-$ and $\mathrm{Br}-$ media by cyclic voltammetry," Journal of Electroanalytical Chemistry, vol. 785, pp. 20-25, 2017.

[12] H. S. Toh, C. Batchelor-Mcauley, K. Tschulik, and R. G. Compton, "Electrochemical detection of chloride levels in sweat using silver nanoparticles: A basis for the preliminary screening for cystic fibrosis," Analyst, vol. 138, no. 15, pp. 4292-4297, 2013.

[13] T. R. I. Cataldi, A. Rubino, M. C. Laviola, and R. Ciriello, "Comparison of silver, gold and modified platinum electrodes 
for the electrochemical detection of iodide in urine samples following ion chromatography," Journal of Chromatography B: Analytical Technologies in the Biomedical and Life Sciences, vol. 827, no. 2, pp. 224-231, 2005.

[14] A. Krklješ, J. M. Nedeljković, and Z. M. Kacarevic-Popovic, "Fabrication of Ag-PVA hydrogel nanocomposite by $\gamma$ irradiation," Polymer Bulletin, vol. 58, no. 1, pp. 271-279, 2007.

[15] I. Stoševski, J. Krstić, J. Milikić et al., "Radiolitically synthesized nano $\mathrm{Ag} / \mathrm{C}$ catalysts for oxygen reduction and borohydride oxidation reactions in alkaline media, for potential applications in fuel cells," Energy, vol. 101, pp. 79-90, 2016.

[16] J. Belloni, "Nucleation, growth and properties of nanoclusters studied by radiation chemistry: Application to catalysis," Catalysis Today, vol. 113, no. 3-4, pp. 141-156, 2006.

[17] G. Ouyang, W. G. Zhu, C. Q. Sun, Z. M. Zhu, and S. Z. Liao, "Atomistic origin of lattice strain on stiffness of nanoparticles," Physical Chemistry Chemical Physics, vol. 12, no. 7, pp. 15431549, 2010.

[18] C. L. Veenas, K. M. Nissamudeen, S. L. Smitha, V. Biju, and K. G. Gopchandran, "Off-axis PLD: A novel technique for plasmonic engineering of silver nanoparticles," Journal of Optoelectronics and Advanced Materials, vol. 11, no. 2, pp. 114-122, 2009.

[19] "MiePlot v.3.4," A computer program for scattering of light from a sphere using Mie theory and the Debye series http://www .philiplaven.com/mieplot.htm.

[20] J. Krstić, J. Spasojević, A. Radosavljević, M. Šiljegovć, and Z. Kačarević-Popović, "Optical and structural properties of radiolytically in situ synthesized silver nanoparticles stabilized by chitosan/poly(vinyl alcohol) blends," Radiation Physics and Chemistry, vol. 96, pp. 158-166, 2014.

[21] A. Motheo, S. Machado, M. V. Kampen, and J. Santos Jr., "Electrochemical Determination of Roughness of Silver Electrode Surface," Journal Of The Brazilian Chemical Society, vol. 4, no. 3, pp. 122-127, 1993.

[22] K. Arai, F. Kusu, N. Noguchi, K. Takamura, and H. Osawa, "Selective determination of chloride and bromide ions in serum by cyclic voltammetry," Analytical Biochemistry, vol. 240, no. 1, pp. 109-113, 1996.

[23] M. Shamsipur, S. Ershad, N. Samadi, A. Moghimi, and H. Aghabozorg, "A novel chemically modified carbon paste electrode based on a new mercury(II) complex for selective potentiometric determination of bromide ion," Journal of Solid State Electrochemistry, vol. 9, no. 11, pp. 788-793, 2005.

[24] Y. Zeng, Z.-H. Zhu, R.-X. Wang, and G.-H. Lu, "Electrochemical determination of bromide at a multiwall carbon nanotubeschitosan modified electrode," Electrochimica Acta, vol. 51, no. 4, pp. 649-654, 2005.

[25] X. Dai, G. G. Wildgoose, and R. G. Compton, "Designer electrode interfaces simultaneously comprising three different metal nanoparticle ( $\mathrm{Au}, \mathrm{Ag}, \mathrm{Pd}) /$ carbon microsphere/carbon nanotube composites: Progress towards combinatorial electrochemistry," Analyst, vol. 131, no. 11, pp. 1241-1247, 2006.

[26] J. Yan, X. Yang, and E. Wang, "Electrochemical detection of anions on an electrophoresis microchip with integrated silver electrode," Electroanalysis, vol. 17, no. 13, pp. 1222-1226, 2005.

[27] I. M. P. L. V. O. Ferreira, J. L. F. C. Lima, and L. S. M. Rocha, "Construction and evaluation of tubular potentiometric detectors sensitive to chloride, bromide, and iodide and based on homogeneous crystalline membranes," Fresenius' Journal of Analytical Chemistry, vol. 347, no. 8-9, pp. 314-319, 1993.
[28] K. Ito, R. Nomura, T. Fujii et al., "Determination of nitrite, nitrate, bromide, and iodide in seawater by ion chromatography with UV detection using dilauryldimethylammonium-coated monolithic ODS columns and sodium chloride as an eluent," Analytical and Bioanalytical Chemistry, vol. 404, no. 8, pp. 25132517, 2012.

[29] S. Bothra, R. Kumar, R. K. Pati, A. Kuwar, H.-J. Choi, and S. K. Sahoo, "Virgin silver nanoparticles as colorimetric nanoprobe for simultaneous detection of iodide and bromide ion in aqueous medium," Spectrochimica Acta - Part A: Molecular and Biomolecular Spectroscopy, vol. 149, pp. 122-126, 2015.

[30] M. Sánchez-Polo, J. Rivera-Utrilla, E. Salhi, and U. von Gunten, "Removal of bromide and iodide anions from drinking water by silver-activated carbon aerogels," Journal of Colloid and Interface Science, vol. 300, no. 1, pp. 437-441, 2006. 

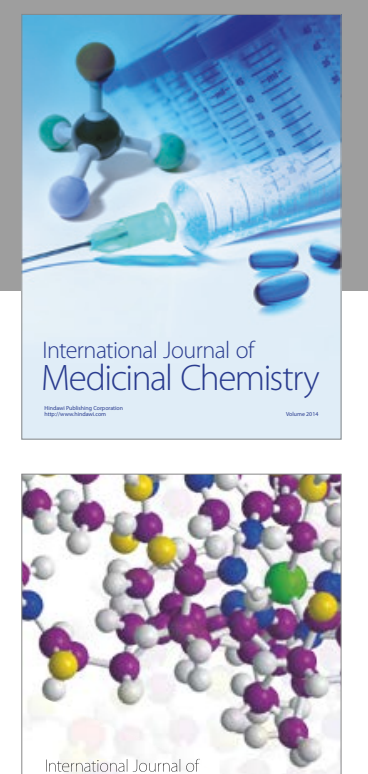

Carbohydrate Chemistry

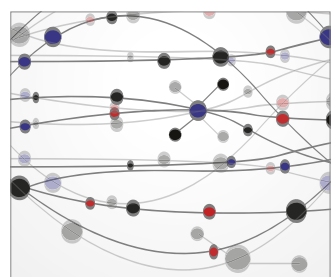

The Scientific World Journal
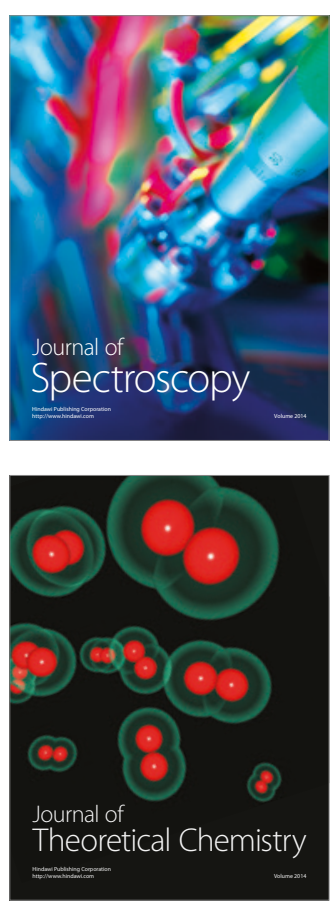
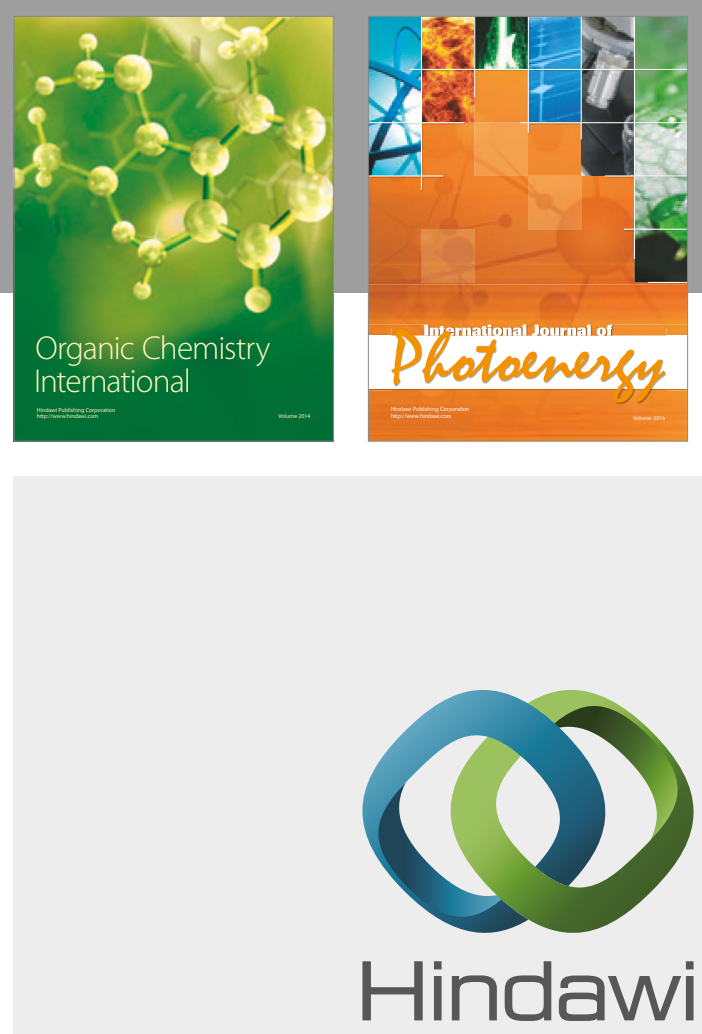

Submit your manuscripts at

https://www.hindawi.com

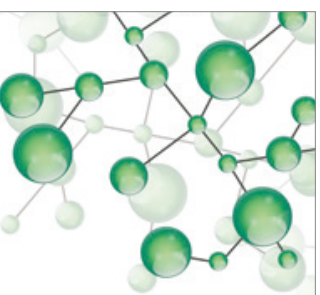

International Journal of

Inorganic Chemistry

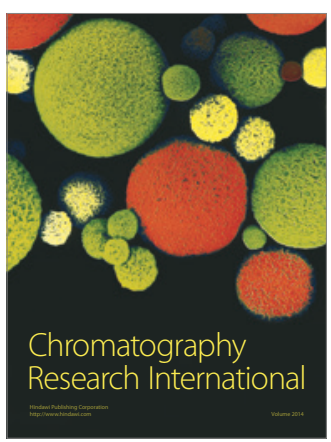

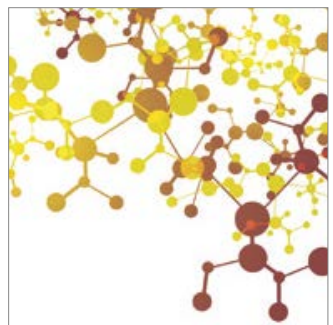

Applied Chemistry
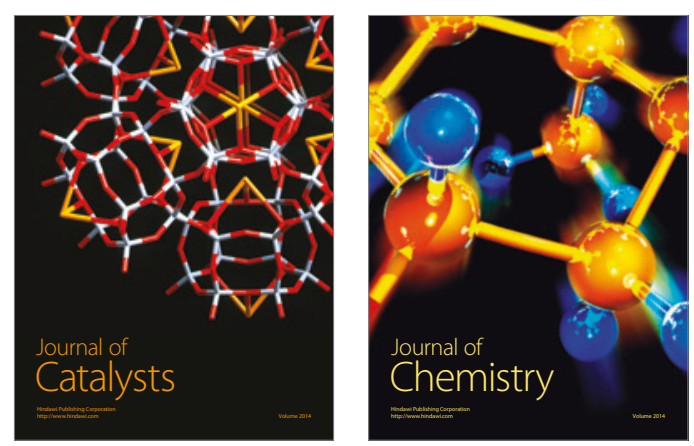
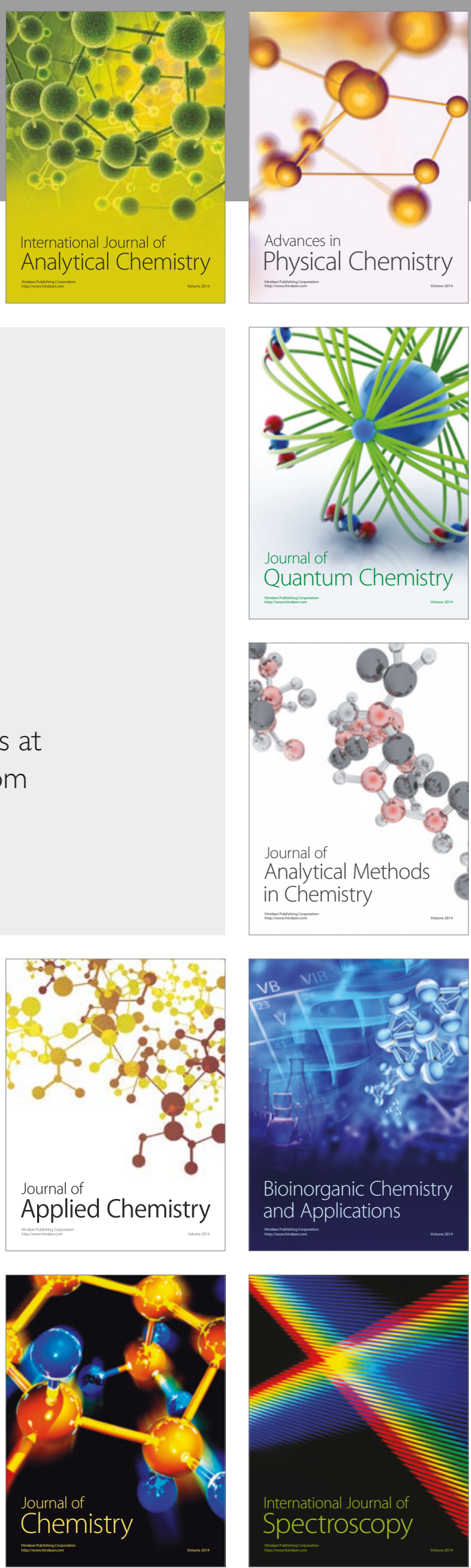